\title{
LEISURE AND QUALITY OF LIFE IN AN INTERNATIONAL AND MULTICULTURAL CONTEXT: WHAT ARE MAJOR PATHWAYS LINKING LEISURE TO QUALITY OF LIFE?
}

(Accepted 26 May 2006)

\begin{abstract}
This paper aims at advancing the conceptualization of leisure as a contributor to quality of life (QOL) in an international and multicultural context, based on an extensive and critical review of literature on leisure and QOL from a global, international perspective. Given the central role of culture in conceptualizing this notion, this paper gives attention to various cultural contexts world-wide. To illustrate the diversity of our societies, examples are introduced specifically from three culturally unique contexts in this paper - i.e., Asian, Middle-East, and Indigenous contexts. Also, some examples are drawn from other cultural groups in global and international contexts, particularly, in non-western contexts. Then, the final section of this paper aims at integrating and synthesizing the knowledge gained from this review to develop a tentative/working proposition about how leisure can contribute to QOL from international and cross-cultural perspectives. Specifically, based on such integration, this paper identifies and describes major pathways linking leisure to QOL. Overall, an overarching theme common to almost all cultural contexts examined appears to be the role of leisure-like activities as a context or space for creating meanings which then help to promote the quality of people's lives. Major pathways or mechanisms that can facilitate meaning-making and lifequality-enhancement highlighted in this review include: (a) positive emotions and well-being experienced from leisure, (b) positive identities and self-esteem gained from leisure, (c) social and cultural connections and a harmony developed through leisure, and (d) leisure's contribution to learning and human development across the life-span. Also, emphasized in this paper is the role of leisure as a context for realizing and utilizing human strengths and resilience. It is important, however, to stress that in people's quest for a meaningful life, the benefits of meaning-making through leisure involve both "remedying the bad" and "enhancing the good," as shown throughout this paper. Despite these benefits, we should not ignore that leisure experiences are socially and culturally constructed and shaped by the inequalities of society. Thus, the reality of power imbalance and inequalities should be acknowledged and appropriately addressed socially, culturally, and politically. Particularly, providing culturally relevant and meaningful leisure opportunities for less privileged population groups world-wide is clearly a top priority.
\end{abstract}

KEY WORDS: leisure, quality of life, culture, meaning, diversity, strength 


\section{INTRODUCTION}

Quality of life (QOL) is a complex yet vague term and, thus, is very difficult to be defined (Cummins, 1998; Veenhoven, 2000). Bramston et al. (2002) and Michalos (2003) all suggested that a little consensus has been made on a definition of QOL, or on the factors that comprise QOL. As emphasized by Lloyd and Little (2005), QOL is "considerably value-laden and values differ across individuals and cultures" (p. 150). Nevertheless, the notion of life quality seems to be concerned primarily with whether people have a good life, and what constitutes a good life (Diener and Suh, 2000; Kovac, 2004), while contemporary definitions conceptualize QOL as a socially and culturally constructed and multidimensional construct that subsumes a number of related factors (e.g., life satisfaction, happiness; Schalock et al., 2002). For example, the World Health Organization (WHO, 1997) defined QOL as 'individuals' perception of their position in life in the context of culture and value system and in relation to their goals, expectations, standards and concerns. It is a broad ranging concept affected in a complex way by the person's physical health, psychological state, level of independence, social relationships, and their relationships to salient features of their environment" (p. 1).

This definition of QOL has proved to be useful in multicultural contexts. For example, with the aim to construct a QOL assessment that would be applicable cross-culturally, the WHO Quality of Life assessment (the WHOQOL) was developed based on an extensive pilot test in 15 centres around the world (Australia, Croatia, France, India, Israel, Japan, Netherlands, Panama, Russia, Spain, Thailand, UK, USA, and Zimbabwe), using over 4,500 subjects. This extensive testing led to the identification of six domains and 29 facets of QOL (The WHOQOL Group, 1998) including: Domain 1. Physical (e.g., pain discomfort, energy and fatigue); Domain 2. Psychological (positive feelings, self-esteem, negative feelings); Domain 3. Level of Independence (e.g., mobility, activities of daily living, work capacity); Domain 4. Social Relationships (e.g., personal relationships, social support); Domain 5. Environment (e.g., physical safety and security; home environment; work satisfaction; financial resources; health and social care; participation in and opportunities for recreation/leisure activities); and Domain 6. Spirituality/Religion/Personal Beliefs. It is worth noting that "participation in and opportunities for recreation/leisure activities" was found to be a significant contributor to QOL based on confirmatory factor analysis, suggesting that leisure activity represents a key element of QOL (The WHOQOL Group, 1998). 
Similarly, the existing QOL literature highlights the role of leisure as a contributor to QOL in studies conducted, for example, in Australia (Lloyd and Auld, 2002), Canada (Michalos and Zumbo, 2003; Michalos, 2005), Iran (Kousha and Mohseni, 1997), Israel (Ritsner et al., 2005), The Netherlands (Wendel-Vos et al., 2004), and Taiwan (Kao et al., 2005). However, our current conceptualization about leisure as a contributor to or a facilitator of QOL is very limited (Lloyd and Little, 2005; Baker and Palmer, 2006). Particularly, we have not yet gained a clear and systematic understanding about "how" leisure contributes to or facilitates QOL. To bridge this gap, a useful and valuable effort may to extensively review the existing literature on leisure, QOL, and related concepts and then, based on the integration and synthesis of such knowledge, to identify major pathways or mechanisms by which leisure can contribute to QOL.

Another key point that must be acknowledged in leisure and QOL research is the fact that "people living in different situations see different things as essential to a meaningful existence" (Shin and Rutkowski, 2003, p. 511), given the diversity of our societies from a global and international perspective. Particularly, culture is, perhaps, the most central and defining concept to characterize our diverse societies (Salzman and Halloran, 2004; Kitaoka, 2005). Thus, conceptualizing leisure and QOL in an international context requires a careful and explicit attention to cultural factors and contexts. Often, culture is broadly defined as the way of life of a society (Gordon, 1964; Wearing, 1998), while leisure is considered an essential part or attribute of culture (Shaw and Karlis, 2002). Gotay (2004) highlighted the need for "an enhanced appreciation of the importance of cultural factors in all aspects of life" (p. 55). Similarly, emphasizing the major role of culture in the conceptualization of QOL, Suh and Oishi (2004) suggested that "the universal strive for a positive life, indisputably takes place within the specifics of the person's cultural environment" (p. 219, emphasis added).

This paper aims at advancing the conceptualization of leisure as a contributor to QOL in an international and multicultural context, based on an extensive and critical review of literature on leisure and QOL from a global, international perspective. Given the central role of culture in conceptualizing this notion, this paper gives attention to various cultural contexts worldwide. To illustrate the diversity of our societies, examples are introduced specifically from three culturally unique contexts (among other cultural contexts) in this paper. First, because a western domination is an apparent phenomenon in both leisure research and QOL research (although efforts to reverse this phenomenon have increasingly been made recently; e.g., Shin 
and Rutkowski, 2003; Leung et al., 2004; Ng et al., 2005), a literature review of this paper gives an explicit attention to eastern regions of the world, particularly, China and some other Asian countries. Gaining eastern perspectives on leisure and QOL is very important to correct the "power imbalance" (i.e., the western domination over east) in leisure and QOL research literature.

Another specific section of the literature review is devoted to leisure and QOL in Middle Eastern contexts. Despite the proximity of the Middle Eastern region to the Asian region, the histories and cultural contexts of the Middle East appear quite unique compared to the rest of the regions of the world (Martin and Mason, 2003). Also, many people in the Middle East seem to be oppressed and disadvantaged historically, culturally, and politically, which has implications for their QOL (Shalhoub-Kevorkian, 2003). Thus, it is worthwhile to give a special and explicit attention to Middle Eastern contexts in order to facilitate an enhanced understanding about leisure and QOL from international and multicultural perspectives.

Another cultural group that deserves a well-respected special attention is Indigenous peoples. One rationale is that Indigenous issues are globally meaningful and important because significant portions of indigenous peoples reside in various regions world-wide who face a variety of pressing health and social problems (e.g., "deep-rooted racism" through the history of colonization; Rock, 2003; Iwasaki et al., 2004, 2005). Another rationale is that there appears to be the distinct division/separation between Indigenous communities and non-Indigenous communities world-wide. Some scholars even suggest that Indigenous peoples live in the fourth world (O'Neil, 1986), being distinct from the third world, which often refers to the regions in developing countries. Hence, it is both important and necessary to focus on and bring forward the perspectives of Indigenous peoples into the conceptualizations of leisure and QOL.

On the other hand, I acknowledge that I should not ignore the perspectives and contexts of other, equally important, cultural groups world-wide. Thus, besides the above three population groups, in this paper I attempt to introduce some examples from other cultural groups in global and international contexts, particularly, in non-western contexts. Then, the final section of this paper aims at integrating and synthesizing the knowledge gained from my extensive review of literature in order to develop a tentative/ working proposition about how leisure can contribute to QOL from international and cross-cultural perspectives. Specifically, based on such 
integration, this paper identifies and describes major pathways linking leisure to QOL.

\section{LEISURE AND QUALITY OF LIFE IN ASIAN CONTEXTS}

Acknowledging the culturally based and complex nature of QOL and its presumed key element, leisure, the following is an extensive review of the literature on these topics from global and international perspectives. The first literature review section addresses leisure and QOL in Asian contexts; specifically, examples are drawn from China, India, and Japan. In terms of China, a distinction is made among the mainland China, Hong Kong, and Taiwan because China is a large diverse country geographically and culturally (Wang, 2005).

From a philosophical and spiritual perspective, Wang and Stringer (2000) described that Taoism as an essential part of Chinese culture strongly influences the lives of Chinese people including leisure. This influence is observable in their close connections to the nature, holistic wellness, traditional and martial arts, literature such as painting and poetry, cultural celebrations, and tourism (e.g., visits to Taoist temples) (Wang and Stringer). Related to these aspects, Yu and Berryman (1996) further indicated that leisure in traditional Chinese society has the following characteristics. Many Chinese show a preference for quiet and reflective activities (e.g., reading books, writing poems, listening to music) rather than the strenuous physical exertion. Also, many Chinese enjoy spending tranquil moments outdoors, appreciating the nature to experience true rest and relaxation, and comprehending the harmony between their inner spirit and the objective world ( $\mathrm{Yu}$ and Berryman, 1996). In fact, facilitating tranquility and peace of mind is an essential element of leisure for many Chinese people, which is linked to understanding the meaning of life (Gong, 1998; Yang, 1998). Historically, both the creation and appreciation of cultural arts such as music, poetry, painting, sculpture, dance, and theater have been a central element of Chinese culture (Wang and Stringer, 2000). Also, Wang and Stringer noted that a number of Chinese festivals (e.g., Chinese New Year, called Guo Nian, as the largest and most important) provide one of the most prevalent opportunities for leisure in China today. Furthermore, somewhat analogous to the western concept of "flow" (Csikszentmihalyi, 1990), "Jing Jie" is considered the highest pursuit of leisure for many Chinese people, which can be experienced through the harmony with the nature and through creative or martial arts, meditation, music, or poem (Gong, 1998; Yang, 1998). These experiences can provide infinite happiness and joyfulness (Wang and Stringer, 2000). 
T'ai Chi is a form of Chinese martial art developed 700 years ago, and adopted by many Chinese as a low cost, safe, and enjoyable form of selfstrengthening and health maintenance exercise (Schaller, 1996). It also provides an opportunity for meditation and spiritual well-being, as well as physical, psychological, and therapeutic benefits (Sandlund and Norlander, 2000), and an opportunity for socialization since it is often practiced in a group (Wolf et al., 1997). Using focus groups with older adults in Hong Kong, Yau and Packer (2002) found that participation in T'ai Chi provides meaning, a sense of structure, rhythm, and pattern to life. For many participants, the early morning practice of T'ai Chi set the tone of the day. Also, T'ai Chi as a form of exercise with its gentle and soft movements was perceived to have a good fit and be appropriate to older adults who want to remain active and healthy (Yau and Packer). In addition, the participants noted that T'ai Chi provides an opportunity for deep meditation to develop an inner calmness and strength, which enables them to deal with adversity or times of stress. Many participants perceived that T'ai Chi has a "meditative effect" to improve their emotional and mental well-being including enhanced cognitive function, and a stronger belief in their ability to take active control over their lives, emotions, and health. As well, many participants highly valued the positive atmosphere of practicing in groups, which provides a place for social support (Yau and Packer). In terms of the term, quality of life (QOL), however, these older Chinese in Hong Kong did not seem familiar with this term (Yau and Packer). But, once explained, they perceived that health, social, and lifestyle benefits through the practice of T'ai Chi are linked to enhanced QOL, while these benefits were perceived to be extended to their family and work life, and daily interactions (Yau and Packer).

Setting a context of her study in India, Nagla (2005) suggested that besides as a major public health issue worldwide, the consumption of food is "an important part of leisure all over the world" because "meal times are usually social occasions when people not only satisfy their appetites but also converse and enjoy each other's company" (Nagla, 2005, p. 24). Particularly, Nagla emphasized that dining in third world villages represents a "leisurely collective ritual" (p. 25). In these villages, extended families and sometimes entire villages congregate for celebrations such as religious festivals, weddings, and birthdays, and food is always central to these occasions (Nagla). Using interviews with 150 households in a rural village and a city district in Harayana State, India, Nagla (2005) explored the practices of and attitudes about food consumption among people in India, in relation to leisure and health. The results suggested that participants value health - good health is 
considered as a condition for maintaining high quality of their lives including family, work, and leisure. The participants also realized that their diets and other lifestyle options (including leisure) strongly influence their health. Highlighting the significance of food and drink consumptions as a context of leisure, Sivan et al.'s (2004) large-scale survey in Hong Kong reported that "the social activities of eating out and going to tea houses" usually with family, relatives, or friends are among the top leisure activities, and retained their popularity and high participation rates (p. 139). In his paper entitled, "Life of Leisure," published in the Far Eastern Economic Review, Jennings (2001) described that "every Chinese city has teahouses and plazas. Here sitting around is a sacred subculture. This scene provides a release from the humdrum. Tea rules the leisure scene, and locals believe it nurtures health" (p. 76).

Based on his analysis of national surveys in Japan, Harada (2004) highlighted Japanese people's "shift toward a more leisure-oriented lifestyle" (p. 153). The 1983 Public Census on Lifestyles (Prime Minister's Office, 1983) recorded for the first time that Japanese people on average considered "leisure" as the most important aspect of daily life, compared to the other aspects of life (e.g., work). In fact, "the proportion of respondents reporting 'leisure' in the highest importance category continued to increase into the 1990s" (Harada, 2004, p. 153). The surveys also suggested that "in the 1980 s, personal preferences shifted away from materialistic concerns to embrace more humanistic values and a desire for a better quality of life" (p. 160). Although by the early 1990s, bubble economy led to economy stagnation, having an impact on leisure attitudes and behaviours of Japanese, public interest in leisure and recreation has continued to grow as facilitated by government policies such as resort developments and shorter working hours (Harada).

From an Indian perspective, Sharma (2002) suggested that "leisure, in the vedantic understanding, would be a state of being as against one of having or doing," and it is seen to be "the realization of human urge for happiness" (p. 18). Sharma also noted that through leisure "the mind is cleansed of impurities" with the "identification of joy and fulfillment" (p. 18). For example, speaking of yoga as "a discipline for the quietening of mental modifications" (p. 19), Sharma (2002) explained that yoga enables one to experience "true self," by aligning the harmony among the body (action), mind (thought), and awareness (spirit). A positive significant association between participation in yoga and QOL was found in Damodaran et al.'s (2002) study in Bombay, India. Having implications for one's QOL, Kumar (2004) described three major goals of human existence in India including: 
hedonistic (pleasure oriented), collective (QOL and wellbeing of an individual as inextricably bound with that of others), and transcendental (QOL and wellbeing in spiritual terms). Furthermore, Sharma suggested that religious rituals and activities can provide a "high degree of leisure," and are considered to be "a powerful cultural force that integrates individuals to the larger society" and keeps people healthy physically and mentally (p. 22).

Leung et al. (2004) conducted a study to explore the components of QOL among elderly Chinese in Taiwan. Their study yielded 15 QOL domains grouped into six dimensions: physical health (physical well-being, impact of illness, medical care), psychological health (mood states, life attitude and retrospection, philosophy of living, self-efficacy), social function (connectedness, exercise and leisure activities, social activities and services), living environment (environment, institutional factors), economic status, and religion and death. Leung et al. found that for elderly Chinese in Taiwan, a person-environment interaction plays a key role in the evaluation of QOL, family ties are a very important aspect of QOL, and traditional Chinese values and beliefs exert a strong positive influence on their perceived QOL. The importance of family ties was also emphasized in Tao et al.'s (1998) study on QOL among elderly Mainland Chinese. Leung et al. (2004) highlighted that "the well-being of both the family as a whole and individual family members was frequently placed as the first priority. This phenomenon is compatible with Chinese culture" (p. 187).

It is important to emphasize that leisure activities such as dancing, Karaoke, Tai-Chi, drawing, and volunteering were identified as a key contributor to QOL in Leung et al.'s study. Speaking of volunteering as a leisure activity, Leung et al. noted that "being able to help others can strengthen the self-perception of competency, and the helping process may also give elderly people a sense of fulfillment and self-satisfaction" (p. 186). Also, these Chinese elderly expressed their vitality by engaging in leisure activities (Leung et al., 2004), while vitality has been recognized as a key component of QOL (Ren et al., 1998). Highlighting the important role of being active in an older life, Kao et al.'s (2005) study with male residents of veteran homes in Taiwan over the age of 65 years reported that during a 2-year follow-up period, 105 of the 689 subjects died, and the mortality rate for the group which exercised "usually/everyday" was significantly lower than the group that "never/seldom" exercised.

Marafa and Yung's (2004) study in Hong Kong provided evidence that leisure (particularly, outdoor recreation) can assist people to "resist the onset of stress reactions in a situation of health scare such as the SARS pandemic" (p. 45). They found that as people attempted to withstand any 
direct or indirect effects of the SARS epidemic, there was a growing awareness of health and environmental issues, and many individuals maintained a healthy lifestyle, a large part of which involved outdoor recreation activities. Marafa and Yung emphasized that in most societies including Hong Kong, "leisure and recreation assumed a major part of people's lifestyle," and "appreciating nature and becoming involved in outdoor recreation is synonymous with promoting quality of life" (p. 41). Yuen's (1996) study in another urban Asian city, Singapore reported that urban parks provide opportunities for social interactions and leisure activities with shared cultural values and meanings. Particularly, Yuen noted that parks have the potential to provide a "backdrop" for public life as a context for spending time with family and friends and participating in various cultural festivals and events, which has implications for promoting QOL.

\section{LEISURE AND QUALITY OF LIFE IN MIDDLE-EASTERN CONTEXTS}

The next section of a review of literature focuses on leisure and QOL in the Middle East, including such countries as Egypt, Iran, Turkey, and Israel. To be described are unique cultural characteristics of this region of the world in relation to the ways and aspects of their lives including leisure, wellness, and life quality.

First, Martin and Mason (2003) explored the relevance of the concept of leisure to three countries in the Middle East, namely, Egypt, Iran, and Turkey, based on their reviews of the literature and available statistics on leisure engaged by people in these countries. They suggested that "leisure time and leisure activities are topics of growing importance for countries of the Middle East with an Islamic tradition" (p. 37). For many people in these countries, however, "leisure opportunities are constrained by the pressures of everyday existence on both time and money available" (Martin and Mason, 2003, p. 42). For example, "recreation and amusements plus hotels and travel account for less than $2 \%$ of Iranian consumer spending, and just over $5 \%$ of that in Turkey, compared with over $17 \%$ in the UK" (p. 44). Martin and Mason noted that this trend partly explains the continued preference on traditional leisure activities with a low spending content, notably socializing (e.g., meal times) with family and friends, and on religious festivals and activities. While this pattern of leisure is still dominant, a relatively affluent urban middle class has developed in all three countries with a gradual increase in a more western pattern of leisure (Martin and Mason). However, "a uniquely Muslim state of mind and its potential influence on leisure behaviour" (p. 45) is evidently very important, whereas 
the prevalence of traditional cultural barriers (e.g., limited participation in sports among women) and the lack of suitable facilities and resources should not be ignored (Martin and Mason, 2003).

Next, Kousha and Mohseni's (1997) study revealed that life satisfaction among Iranian women $(n=335)$ in urban areas is directly linked to their satisfaction with leisure experiences. A major conclusion from their study, however, was that "elements that affect Iranian women's satisfaction are complex; they are the byproduct of the interaction of complex personal, traditional, and societal forces that shape women's role in the society" (p. 345). For example, as a form of leisure, shopping involves spending time with family and friends and entering into "negotiations with shopkeepers and clerks, a cultural maneuver occurring in most purchases, be it clothing or groceries" (p. 347). More importantly, shopping also illustrates women's economic independence and spending capacity (Kousha and Mohseni). Whereas the economic depression of the last decade and the 8-year war have negatively affected many Iranians' lives including their leisure, Kousha and Mohseni found that "getting together with family and friends appears to be one, if not the most, important pastimes of people" (p. 345). Furthermore, as illustrated in an example of shopping above, "being able to devote some time to leisure, in whatever form or shape, signifies women's efforts to spend time the way they wish and their attempt to overcome culture barriers toward leisure" (p. 345). Besides other markers of life such as gender, class, age, ability/disability, and sexual orientation, culture does shape the ways in which Iranian women define leisure (Kousha and Mohseni, 1997), and "the experience of leisure is in itself crucial to Iranian women's lives" (p. 344).

More recently, Sheykhi (2004) observed that cultural changes due to the development of new institutions and globalization have happened to Iran in recent decades, similar to many other developing societies. He suggested that this phenomenon has triggered new expectations among people in Iran, including the need for leisure and tourism as a high priority. Sheykhi, however, cautioned that with the absence of an infrastructure, the situation is complicated and controversial. Nevertheless, a key message emphasized is that "in Iran leisure is viewed as having a determining impact on quality of life. It is regarded as a vital contributor to quality of human functions and duties" (p. 62), whereas understanding unique cultural features is essential to promoting the QOL of people in Iran and other Islamic countries. For example, Sheykhi described religious and cultural tourism in Iran. He observed that a growing number of Muslim tourists from the Middle East, south, central, and even east Asian countries visit Islamic monuments in Iran. Sheykhi suggested that this form of religious and cultural tourism can 
provide an opportunity to enhance the QOL of many different population groups. Also, Sheykhi brought other examples such as: the role of leisure among adolescents in facilitating creativity, exploration, and education, as well as the reemergence of old leisure repertoires (e.g., painting) among some older women following the completion of their child rearing and domestic responsibilities (Shoarinezhad, 1994). Sheykhi concluded that "leisure and tourism are considered as activities essential to the life of the Iranian nation, because of their direct social, cultural, educational and economic benefits. Proving for it would contribute to further individual and social health, national unity, and integration" (p. 66).

In Israel, Ritsner et al. (2005) used the QOL Enjoyment and Satisfaction Questionnaire (Q-LES-Q) in their study with 339 schizophrenia or schizoaffective/mood disorders patients who were either Jewish or Arab Israelis. Notably, Ritsner et al. found that leisure is one of the four factors essential to QOL derived from their factor analysis on the Q-LES-Q, the other factors being social relationships, physical health, and subjective feelings. Also, it is important to emphasize that leisure time activities in the Q-LES-Q were significantly associated positively with self-efficacy, self-esteem, and social support, and negatively with depression and emotional distress.

Finally, Shalhoub-Kevorkian's (2003) study aimed at uncovering the voices of mothers of martyrs in Palestine who were destined to cope with the agony and trauma of losing a child. These Palestinian women participated in an empowerment group (termed a "voice therapy") which provided a safe context for the women to unveil their narratives and feelings in order to liberate these voices. Particularly, Shalhoub-Kevorkian found that building connections among Palestinian women who have suffered in a similar way was an essential part of healing and recovery. These women valued this group in a family context because their ways of coping with their losses centred around helping and supporting each other like family members do, as illustrated by the following quote, "when I see the family content, it eases my pain." In this family-like context, these women involved in activities with other mothers of martyrs such as "songs, gatherings, food, talks," (p. 402), "praying" (p. 400), "poetry," and "writings" (p. 405). Shalhoub-Kevorkian described that "despite the enormous trauma inflicted upon these mothers, and the continued incapacitation by political and social institutions, they did not break down" (p. 404). Rather than becoming passive victims, they proactively became "creators of safety nets" and demonstrated their strengths in the company of other women (p. 404). As a result, this empowerment group became "a safe milieu," filled with care, love, support, protection, and hope (Shalhoub-Kevorkian, 2003, p. 404). 
The descriptions presented by Shalhoub-Kevorkian resemble Wearing's (1998) notion of "leisure space." Discussing this notion, Wearing introduced examples of writing, poetry, art, dance, singing, story-telling, and humour engaged by Aboriginal Australian women and Bosnian women refugees, which provided a context for finding meaning of life, and facilitating personal growth and empowerment. The detail about Wearing's (1998) idea of "leisure space" will be provided in the next section of Leisure and Quality of Life in Indigenous Contexts.

\section{LEISURE AND QUALITY OF LIFE IN INDIGENOUS CONTEXTS}

According to Salzman and Halloran (2004), despite the oppressive colonial systems burdened historically on Indigenous peoples throughout the world, they are regaining cultural recovery and meaning by seeking their traditional cultural worldviews. Salzman and Halloran described this aspect by introducing examples from the lives of Native Hawaiians, Native peoples of Alaska, and Aboriginal Australians. First, Salzman and Halloran noted that the Hawaiian renaissance period (late 1960s to 1970s) was characterized by the recovery of traditional rituals and ceremonies including "the revival of hula, language and culture study, music, and traditional forms of healing," as well as arts, crafts, and literature, which served to reconstruct cultural and spiritual meanings for Native Hawaiians (Salzman and Halloran, 2004, p. 238). As written by Kanahele (1982), this helped to reassure their identity and inspired stronger pride in their culture, and Hawaiians continue to thrive in traditional and modern evolutions of Hawaiian culture.

As for cultural recovery among Native peoples of Alaska, efforts have been made to recover "core values such as sharing, respect for elders, cooperation, respect for others, avoidance of conflict, respect for nature, spirituality, and humor" (Salzman and Halloran, 2004, pp. 238-239). In terms of cultural recovery among Aboriginal Australians, rebuilding indigenous culture, for example, through the use of traditional healing ceremonies seems effective and culturally appropriate to address problems (e.g., health-related) and facilitate healing among them (Atkinson and Ober, 1995; Tsey and Every, 2000). In these cases, indigenous cultural recognition and recovery with the aim of promoting greater harmony and meaning making is essential to their health, well-being, and QOL (Canales, 2004; Salzman and Halloran, 2004).

As an example of the quest for meaning making in an indigenous context, Lopez et al. (2002) emphasized the important role of spirituality and suggested that "Native American spirituality involves the belief that all things 
are connected and are worthy of respect" (p. 705). Often, the lives of indigenous peoples are guided by seeking harmony and balance among interrelated thoughts, emotions, behaviors, and the nature (Lopez et al., 2002). Consequently, living a meaningful life involves "maintaining and contributing to the reciprocal balance of family, clan, tribe, and community in the context of personal, social, and natural environment" (Garrett and Myers, 1996, p. 99).

Balsam et al.'s (2004) study on urban American Indian and Alaskan Native (AIAN) adults including lesbian, gay, bisexual, and two-spirit participants provided evidence that their traditional cultural and spiritual practices (e.g., daily prayers or meditation, pow-wows, memorial feasts, and ceremonies) can act as a buffer against the stresses experienced by AIAN. Also, in an indigenous context, Thompson and Gifford (2000) suggested that both family social system (active role in family; e.g., preparing or sharing of "family food") and community social system (active role in community; e.g., active maintenance of links with extended family and the environment) can "protect the individual through real and symbolic connection to family, community, land, and past, and therefore decrease an individual's vulnerability" (p. 1464).

In her book entitled, "Leisure and Feminist Theory," Wearing (1998) discussed her notion of "leisure space," by describing personal narratives about the lived experiences of Aboriginal women in Australia. She argued,

The spaces that they make in their day for themselves through activities such as reading, writing, poetry, art, and music and dialoguing with other women are a matter of survival, as well as chance to expand the self and relate to others .... The concept of leisure as 'personal space' can incorporate both individual and autonomy and values of interpersonal and community relationships that are so important to colonized women. It can also incorporate possibilities for political action. (p. 167)

Wearing (1998) suggested that although Aboriginal women in Australia did not use the term leisure, it is "woven into their everyday lives as a physical and metaphorical, personal and communal space which has a meaning for them" (p. 167). She introduced comments made by several Aboriginal writers who talked about activities such as sewing, craft circle, storytelling, poetry, painting, and the use of humour and laugher, which provided a personal or collective space for affirming self-worth, autonomy, pride, and strength; for releasing stress and tension; and for gaining community spirit. Furthermore, Wearing showed that activities like poetry, arts, Aboriginal music, and Aboriginal dance which begun in a personal space expanded and became "political tools to make the voices of Aboriginal women heard in the public arena and their needs heeded, which enable communal action" (p. 174). 
Based on their extensive review of the literature, McDonald and McAvoy (1997) indicated that leisure of Indigenous peoples is inseparable from and well reflective of pervasive worldviews maintained and valued widely by Indigenous populations. According to McDonald and McAvoy, the elements of these worldviews include: (a) the belief in the sacredness of life, emphasizing the spiritual aspects of individuals, communities, and the nature; (b) a reciprocal and interdependent relationship with all creations that values harmony and balance; (c) a heightened sense of place or connection to the land/environment; and (d) the cyclical pattern of life exemplified through cultural rituals and traditions. McDonald and McAvoy then admitted that these "well be found in leisure as well" (p. 161). For example, dance, music, sport, art, religion, and spiritual practices by Aboriginal persons have been identified to have connotations with the above worldview elements (McDonald and McAvoy).

Also, the centrality and meaning of place among Indigenous peoples should not be ignored, which has implications for nature-based recreation and tourism. In their case study using archive materials and interviews on place attachment to park lands among First Nations people in British Columbia, Canada, McAvoy et al., (2003) found that First Nations people hold "deep emotional, symbolic and spiritual meanings of places that ... influence their lifestyles, environment, and perceived quality of life" (p. 100). Specifically, the spiritual nature of life and the land, as well as the collective orientation of Aboriginal peoples were highlighted as essential and pervasive to all aspects of life including leisure. Similarly, Fox and colleagues (1998) noted that "leisure is integral to Aboriginal culture and cannot be separated from the spiritual, cultural, social, and physical connections" essential to Aboriginal peoples (p. 152).

The National Recreation Roundtable on Aboriginal/Indigenous People was held in Maskwachees, Canada in February 2000. Its purpose was to adopt a holistic approach through an understanding of Aboriginal cultures and traditional lifestyles, while exploring how recreation and leisure can be used to preserve Aboriginal culture, promote balance, and enhance the quality of their lives (Karlis, 2004). As clearly documented in the Maskwachees declaration, the delegates of the roundtable recognized that leisure and recreation is vital for health, wellness, cultural survival, and QOL of Aboriginal/Indigenous peoples, as well as for addressing social issues encountered by Aboriginal communities (e.g., poverty, health concerns) in Canada and around the world. 


\section{LEISURE AND QUALITY OF LIFE IN OTHER CULTURAL CONTEXTS}

The literature reviewed up to this point demonstrates the centrality of leisure as an element of or a contributor to QOL of people in three distinct cultural contexts: Asian, Middle-Eastern, and Indigenous. Given the global and international nature of leisure, this section attempts to explore leisure and QOL in other cultural contexts worldwide. Not only are examples from different countries drawn to further describe the nature of leisure and QOL, but attention is also given to unique individual characteristics and identities including the lived experiences of people with disabilities, those living with chronic illnesses, elderly, and individuals with unique sexual orientation.

First, a literature review paper by Bramante (2004) indicated that people in Brazil value gaining meaningful leisure experiences as a "significant human life dimension" (p. 225). Similarly, commenting on leisure in Brazil as a cultural manifestation, Cabeza (2000) described his "humanistic concept of leisure in its solidarity dimension, emphasizing its altruistic and social coexistence" (p. 231). Stebbins and Graham's (2004) recent book that highlights "the international volunteer scene" from various countries including Britain, Brazil, Canada, Australia, the Netherlands, and USA, lent extensive support for the idea of volunteering as leisure in the forms of serious, casual, or project-based, which can provide a variety of benefits including the promotion of individual and community QOL.

Based on their study with 1,654 Batswana aged 15-30 years, Amusa et al. (2001) showed that "leisure is a necessary part of life" among many young Batswana (p. 271). Within a unique cultural context of Batswana, Amusa et al. suggested that participation in indigenous games, pastimes, and sports is important for youth to restore and maintain "the cultural values of the country" (p. 289), to counter "ever increasing everyday social problems" such as poverty (p. 271), and to improve "the quality of life of the people" (p. 288). Amusa et al. argued that these activities can provide "opportunities for enjoyment, entertainment, meaningful involvement in community activities, success and being valued as a person" (p. 271) to achieve these goals. Because they found that the respondents had very limited knowledge about the concept of leisure and the role of leisure in their lives, they emphasized the importance of leisure education for young Batswana including the use of leisure as a developmental tool. The findings, however, indicated that many respondents seem to recognize recreation and leisure as "a valuable tool for social improvement and economic development" (p. 288) although there is the need to provide better infrastructures and facilities. 
According to Stathi and Avgerinos (2001), health tourism (i.e., travel for health and well-being) is a growing industry world-wide due to an increased interest in and a rising demand for alternative medical treatments. Particularly, Europe is well known for its "spa baths and the therapeutic power of thermal waters" where Germany, Italy, and France are the popular destinations in Europe for health tourism (Stathi and Avgerinos, 2001, p. 42). Such popularity and growth in health tourism is understandable because "the natural environment affects human health" (Stathi and Avgerinos, 2001, p. 41). For example, Sukenik et al. (1999) found that natural cures including Spa therapies contribute to better health and QOL.

As an important outcome from the Fifth World Leisure Congress held in Sāo Paulo, Brazil in October 1998, a book entitled "Leisure in a Globalised Society" features a collection of papers written from a global, international perspective. Some selected papers are briefly summarized here. First, based on her analysis of the connection between leisure and urban space in Campinas, Brazil, Rolnik (2000) suggested that leisure is socially and culturally embedded in the city and is recognized as an important public dimension. Rolnik also emphasized the function of leisure as a significant anti-exclusion instrument, consistent with the European Union's (EU) approach to social inclusion (Ravenscroft et al., 2005). Also, as an UNESCO's representative from Brazil, Werthein (2000) noted that the constructive use of free time, particularly, meaningful forms of leisure participation, is an important part of the reconstruction process in Brazil, which is driven by the culture of peace and solidarity.

Mantero (2000) suggested that leisure is a symbolic activity in community life of people in Argentina that generates and integrates meanings of life. Particularly, Mantero emphasized that cultural spaces are an essential context for people to enjoy leisure best. Mantero also argued that in these cultural spaces meaningful to people in Argentina, leisure can provide an opportunity to rest, regain balance, and facilitate growth and development at both personal and social levels. In their action-research project in BocaBarracas, Argentina, Moore and Cosco (2000) examined the role of women in supporting "rich lives in poor neighbourhood," by focusing on culture and children's opportunities for play. Their study highlighted the critical aspect of immediate and extended families and supportive institutions to provide a space for play and cultural activities in order to enrich cultural identity of children from low income families and overcome marginalized living conditions (i.e., poverty). However, Rondon (2003) cautioned that "efforts at improving quality of life for women in Latin America should include consideration of local cultural, political and economic peculiarities" 
(such as violence against women and girls) that have been prevalent historically in Latin America (p. 157).

Kloeze (2001) explored the nature and role of leisure in the lives of Turkish families in Dutch cities. Kloeze found that even after several generations, these Turkish families are still strongly oriented towards their original cultural traditions, values, and ways of life. It was shown that their free time is spent frequently with family members, which can take place within the neighbourhood or city (e.g., "meadows and parks"), outside the city, in nearby countries, or even visiting family in the original homeland, Turkey. Demonstrating the cultural tradition in Turkish society, this study revealed that the lives of Turkish families are strongly shaped by genderbased power imbalance. This unequal power relation is evident in their leisure domain, and the notion that married women have the right to free time is not strong among Turkish women. For example, mosque and café are a popular place for leisure, but only for Turkish men, not for women (Kloeze, 2001).

Based on his own research and a review of literature on serious leisure (such as amateurism, hobbies, and volunteering) among individuals with disabilities world-wide, Patterson (2001) suggested that this type of leisure forms "the basis for self-respect and self-esteem and leads to greater acceptance and social inclusion in the community" (p. 16), which can then promote greater QOL for people with disabilities. Also, Nosek et al.'s (2004) study on women with physical disabilities provided evidence that the engagement in rewarding leisure activities helped them promote self-esteem and self-fulfillment, and experience greater life satisfaction. In Bishop's (2005) study, leisure activities were identified as one of the 10 domains of QOL in a QOL-based model of psychosocial adaptation to chronic illness and disability, which represents "a conceptual synthesis of several existing theories and models, drawn from the quality-of-life, rehabilitation counseling, and rehabilitation psychology literature" (p. 219).

Silverstein and Parker (2002) analyzed a longitudinal national sample of 324 community-living Swede elderly, who were surveyed in 1981 and 1992, to examine their leisure participation during their transition to late old ages. These researchers found that meaningful leisure activities helped Swede elderly adapt to a period of later life and promote QOL "when deficits in physical and social resources place older adults at greater risk of disengagement and distress" (p. 546). Wendel-Vos et al., (2004) conducted a longitudinal analysis of data from 2,129 participants living in three towns in The Netherlands (1995-1996 and 2000-2001), and found a significantly positive association between an increase in leisure time physical activity and 
an improvement in health-related quality of life for social functioning among both men and women.

In his participatory action research that used documentary photography and storytelling, Graziano (2004) found that gay men and lesbians in South Africa show signs of strength, hope, and optimism despite the prevalence of oppression and adversity in their lives. Particularly, he reported that "warm and friendly interactions with family and friends" and "safe, social spaces" (e.g., Black churches) play a key role in challenging discrimination, fighting social injustices, honoring life, and maintaining hope. One participant of his study mentioned, "I am satisfied with the happiness I have. I will remain strong" (p. 311). Also, Bowleg et al.'s (2003) study revealed that one way that racial and sexual minority women demonstrate resilience is tied to the meanings that they attach to their experiences. For example, several participants emphasized the uniqueness of being a Black lesbian, while others valued the freedom or liberation that they experienced (e.g., through social leisure activities), which enabled them to live according to their own desires, rather than following societally prescribed stigma.

Wearing's (1998) notion of leisure space, described earlier in the context of Aboriginal Australians, has also been shown to be relevant to explaining the strengths and resilience of people in various cultural contexts worldwide. For example, Wearing (1998) illustrated the lives of Bosnian women refugees who created spaces for themselves and fellow refugees, by engaging in voluntary activities, knitting, and sewing to gain "meaning for survival, self-respect, support and communal agenda" (p. 173). One Bosnian female refugee commented, "I discovered so much about myself. I am a strong woman. When I look at other refugees, I see many strong women" (p. 172). Wearing summarized,

They can speak of their everyday experiences and of the strategies they use to counter their subordination. They do not speak of leisure in the conventional sense of the term as non-work, but rather of their own ways and means of making spaces for themselves and meaning for their lives in oppressive circumstances. Leisure as personal space provides an avenue for self-expansion, which has the possibility of moving from the self to others and to communal action. (p. 173)

Recently, Lloyd and Little (2005) conducted a qualitative, interpretive study to examine the meaning of QOL for women who participated in an outdoor adventure recreation program, and its relationship to leisure (particularly, outdoor adventure recreation). Their participants were 20 women in Brisbane, Australia, of whom three were unemployed, and two of the unemployed women were with physical disabilities. The program these women participated was called "Real Adventure Women (RAW)," which has provided "an opportunity to try outdoor activities in non-competitive and 
supportive environment" (p. 147). Lloyd and Little found that these women understood QOL as the combination of: access to opportunities (which involves financial security, affordability, and the ability to make choices), maintaining a positive attitude toward life, developing a positive self-perception, finding balance in life, and experiencing social belonging. Also, they found that participation in RAW contributed to greater QOL, with a specific impact on four of these factors by offering an opportunity for: access to new opportunities, improved self-perception, finding a sense of balance, and experiencing a sense of belonging. For example, concerning a positive selfperception, participants mentioned greater confidence, a sense of achievement, doing something for themselves, and feeling better about themselves as key outcomes from these experiences, as illustrated by one person commenting, "You understand yourself better, and you then understand other people better" (Lloyd and Little, 2005, p. 170).

6. CRITICAL EXAMINATION OF LEISURE AND QOL IN AN INTERNATIONAL AND CROSS-CULTURAL CONTEXT: WHAT ARE MAJOR PATHWAYS LINKING LEISURE TO QOL?

Based on the above extensive literature review on leisure and QOL in various cultural contexts, in this concluding section I attempt to integrate/ synthesize and make sense of this diverse collection of evidence by highlighting major pathways or mechanisms by which leisure can contribute to people's QOL from international and cross-cultural perspectives. Overall, an overarching theme common to almost all cultural contexts examined above appears to be the role of leisure-like activities as a context or space for creating meanings which then help to promote the quality of people's lives. To describe this overarching theme, however, it becomes clearly evident from the above review that culture plays an essential role in facilitating this meaning-making and life-quality-enhancing mechanism of leisure. Particularly, meaning-making through leisure seems to be concerned with personal, social, cultural, spiritual, altruistic, and developmental meanings generated from a variety of leisure-like pursuits relevant to a particular cultural context. Consequently, this meaning-making through leisure appears to facilitate the promotion of QOL in culturally appropriate ways. These observations seem to be supported by the extensive review of literature documented above in various cultural contexts world-wide. In this section, I critically discuss this meaning-making and life-quality-enhancing mechanism of leisure at a conceptual level, built from the collection of evidence 
from around the world presented above, in comparison to the existing knowledge about leisure and QOL from additional sources of literature.

\subsection{Meaning-Making through Leisure in Cultural Contexts}

Understanding how people gain meanings through leisure is considered a major research agenda in leisure studies (Samdahl and Jekubovich, 1997), given that "searching for meaning is the primary motivation in life" (Frankl, 1985, p. 121). It has also been acknowledged that such understanding has implications for the value and contribution of leisure to the QOL of people and their communities (Juniu and Henderson, 2001).

\subsubsection{Positive Emotions and Well-being Experienced from Leisure. One} major source of meaning-making through leisure seems to be positive emotions and wellbeing gained from leisure pursuits. As shown above in the review of literature in various cultural contexts and also emphasized by Folkman and Moskowitz (2000) and Hutchinson (2004), people can find positive meaning within ordinary daily events and activities (e.g., social leisure, spiritual leisure) by discovering positive values and having positive experiences from these events and activities. For example, as noted earlier, Yau and Packer's (2002) study with older adults in Hong Kong highlighted a "meditative effect" of T'ai Chi to enhance their emotional and mental well-being (e.g., cognitive function, control over their lives). Also, Gong (1998) and Yang (1998) suggested that facilitating tranquility and peace of mind is an essential element of leisure for many Chinese people (e.g., hiking in the mountains, visiting a temple, or drinking tea or wine), which is tied to understanding the meanings of life. In terms of the origin of positive emotions, Frederickson (2002) suggested that "positive emotions results from finding positive meaning" (p. 130). Supporting this idea, Tugade and Frederickson's (2004) study provided evidence that the experience of positive emotions contributed, in part, to people's abilities to achieve emotional regulation, by finding positive meanings in negative, stressful circumstances. Finding positive meanings can also have significant therapeutic effects, such as recovery from depressed mood and distress and improvements in health and well-being (Keltner and Bonanno, 1997; Davis et al., 1998). In fact, Frederickson's (2002) "broaden-and-build" theory of positive motions rests on the idea that "positive emotions are markers of optimal well-being" (p. 120).

6.1.2. Positive Identities and Self-esteem Gained from Leisure. Through finding positive meanings in life, one seems to be able to maintain positive 
identity and self-esteem. The literature review documented above contains a number of examples to suggest that leisure can provide a context for people with different cultural backgrounds to enhance their self and social identities, which are tightly linked to promoting their self-esteem. For example, speaking of Native Hawaiians, Native peoples of Alaska, and Aboriginal Australians, Salzman and Halloran (2004) described how the engagement in Indigenous activities such as music, arts, crafts, literature, and traditional ceremonies and festivals can facilitate to reassure their identities, inspire stronger pride and self-esteem, and regain cultural recovery and meaning. Also, as noted earlier, Ritsner et al.'s (2005) study on Jewish or Arab Israelis with mood disorders reported that leisure time activities were significantly and positively associated with self-esteem. Generally, self-esteem is a construct related to how an individual values oneself (Porter and Washington, 1993). According to Hewitt (2002), self-esteem is an element of a culture, and "the language of self-esteem translates deeply rooted cultural issues into personal terms" (p. 139).

\subsubsection{Social and Cultural Connections and a Harmony. Another key} meaning-making mechanism through leisure seems to involve social and cultural connections in interpersonal and community contexts and a harmony with the environment. In fact, the above review of literature presented is filled with a number of culturally relevant examples to suggest that social and environmental connections developed through leisure contribute to meaning-making and life-quality-enhancement. For example, besides the central role of family ties in various cultural contexts (e.g., Middle-East; Martin and Mason, 2003), Wang and Stringer (2000) described that Taoism, which strongly influences the lives of many Chinese people including leisure, values a close connection to the nature, holistic wellness, arts, literature, cultural celebrations, and spiritual tourism (e.g., visits to Taoist temples). Also, Sharma (2002) indicated that maintaining the harmony among the body (action), mind (thought), and awareness (spirit) is essential in yoga to experience "true self," while a positive significant association between participation in yoga and QOL was found in Damodaran et al.'s (2002) study in Bombay, India. Consistent with such evidence, Baumeister and Vohs (2002) argued that "the essence of meaning is connection" (p. 608), while Lopez et al. (2002) suggested that seeing "the possible connections among things, events, and relationships" is important to achieve life meaning (p. 705). Ryff and Singer (2000) emphasized that having quality ties with others is "a core feature of quality living across cultures and across time" (p. 30). For example, as noted in the above literature review, Nagla (2005) described the 
role of dining among extended families in third world villages as a "leisurely collective ritual" (p. 25).

6.1.4. Quest for a Meaningful Life: Major Needs for Meaning. Based on his extensive review of evidence from several scholarly fields, Baumeister (1991) concluded that the quest for a meaningful life can be facilitated by four main needs for meaning. The first need is for purpose. This need is concerned with the connection between the present and the future, while goals and fulfillments are critical elements of purpose. The second need is for values, which can "lend a sense of goodness or positivity to life and can justify certain courses of action" (Baumeister and Vohs, 2002, p. 610). The third need is for a sense of efficacy, which is facilitated by "a belief that one can make a difference" and can control over their lives and themselves (Baumeister and Vohs, 2002, p. 610). The fourth and last need is for a basis for self-worth. Pursued individually or collectively, "most people seek reasons for believing that they are good, worthy persons" (pp. 610-611). Baumeister and Vohs (2002) emphasized that culture does offer varied and powerful means of satisfying the needs for meaning and of facilitating one's quest for a meaningful life. As evident in the review of literature documented above, leisure does seem to provide an opportunity to satisfy all of these needs in culturally meaningful ways. For example, Lopez et al. (2002) and McDonald and McAvoy (1997) emphasized the centrality of spirituality in Indigenous peoples' search for meaning in life, since spirituality guides them to assure the purpose and value in life and to find self-worth and control over their lives. Also, Harada (2004) showed that many Japanese people have increasingly acknowledged leisure as a most important aspect of their lives in order to satisfy their need for more humanistic values and their desire for a better QOL.

\subsubsection{Benefits of Meaning-making: Remedying the Bad and Enhancing the} Good. According to Baumeister and Vohs (2002), the power of a meaningful life "goes beyond the fact that meaningfulness reduces suffering"; meaning making is powerful "both for remedying the bad and for enhancing the good" (p. 616). In fact, meaning-making is integral to happiness, fulfillment, and other forms of positive well-being, while a meaningful life is itself a highly positive outcome (Baumeister and Vohs). This idea seems particularly relevant to leisure as a means of dealing with life difficulties and of producing positive outcomes in various cultural contexts, as shown in the literature review presented above. For example, Shalhoub-Kevorkian (2003) found that despite the trauma of losing a child, Palestinian mothers of 
martyrs "did not break down" and proactively became "creators of safety nets" and showed their strengths in the company of other women, filled with care, love, support, protection, and hope (p. 404), through being involved in such activities as songs, gatherings, praying, poetry, and writing. In their study on QOL among Chinese elderly in Taiwan, Leung et al.'s (2004) analyses identified leisure as a key contributor to QOL, particularly as a means of expressing their vitality by engaging in such activities as dancing, Karaoke, Tai-Chi, and drawing.

\subsubsection{Human Strengths and Resilience as a Pathway to Meaning-making} and Life-quality-Enhancement. Extended from the above discussion and widely demonstrated in the literature review above, another key aspect of leisure is that it can provide a context for revealing and utilizing personal, collective, or cultural strengths of people to deal with life challenges. For example, Salzman and Halloran (2004) and Wearing (1998) showed that despite the oppressive colonial systems historically affecting Indigenous peoples throughout the world, they are regaining cultural and spiritual recovery and meaning through the involvement in Indigenous music and dance, arts and crafts, storytelling and literature, traditional rituals, and the use of humour and laugher. Lopez et al. (2002) argued that identifying "the diverse strengths of individuals and cultural groups" and valuing "diverse meanings of the good life" can encourage "optimal functioning of individuals and communities" (p. 700). Clearly, there is the need to acknowledge human diversity and broadly deal with racial, ethnic, and cultural issues by recognizing "unique differences, strengths, and histories" because cultural factors strongly influence the meanings of life and the clues to the good life (Lopez et al., 2002, p. 702). As reminded by Chin (1993), each person has a unique culture, both independently and connected to the larger society. The central role of human strengths and resilience as a pathway to meaningmaking and life-quality-enhancement is consistent with Ryff and Singer's (2003) argument that

It is not the absence of negative experience or negative emotion that defines the good, welllived, richly experienced life, but how challenges and difficulties are managed, dealt with, and transformed... The deepest levels of human meaning and connection are frequently found when individuals come face to face with their vulnerabilities, insecurities, or pain... through profiles of action and reaction that deepen self-knowledge and meaning, enrich social bonds, and expand personal effectiveness (p. 279).

Ryff and Singer also suggested that "engaged living" through the use of human strengths in dealing with life challenges is a "core ingredient of life quality" (p. 282). As evident elsewhere in this paper, leisure appears to act as 
one essential facilitator to this strength-based pathway leading to meaningmaking and life-quality-enhancement. For example, as described earlier by Yau and Packer (2002), T'ai Chi as a form of Chinese martial art provides an opportunity for deep meditation to develop an inner calmness and strength, which can help to deal with challenges in life. Also, Marafa and Yung's (2004) study in Hong Kong provided evidence that leisure can act as a valued buffer against stress at the time of health scare such as the SARS pandemic. Based on their study with Iranian women, Kousha and Mohseni (1997) suggested that leisure can provide these women with an opportunity to "spend time the way they wish and their attempt to overcome culture barriers" (p. 345). For example, they described the act of shopping, which not only involves spending time with family and friends, but also shows women's economic independence and power.

The resilience of gay men and lesbians in South Africa was emphasized in Graziano's (2004) participatory action research, particularly, through "warm and friendly interactions with family and friends" and "safe, social spaces" (e.g., Black churches) as a way of dealing with oppression and maintaining hope (p. 311). Also, Wearing (1998) showed that Bosnian women refugees created spaces for themselves and fellow refugees, by engaging in such activities as volunteering, knitting, and sewing not only to gain meanings for survival, self-respect, and self-enlargement, but also to have an impact on community empowerment and political activism at a broader level.

\subsubsection{Human Development Across the Life-span. Furthermore, the con-} tribution of leisure to learning and development across the life-span is another key theme relevant to almost all cultural contexts reviewed in the previous sections. For example, Amusa et al. (2001) emphasized the importance of leisure education for young Batswana including the use of leisure (e.g., Indigenous games, pastimes, and sports) as a developmental tool, and its contribution to strengthening their cultural identity and QOL. According to World Leisure (2000a) position statement on leisure education and community development, leisure opportunities are considered "conducive for learning," "leisure is a most valued component of community development inter-culturally," and meaningful and lifelong leisure (including serious leisure) provides "opportunities for self-actualization, self-definition and self-determination and further contribution to the quality of community life" (p. 55). In addition, emphasizing "the universality of need for leisure" (p. 57), World Leisure (2000b) position statement on leisure education and populations of special needs indicated that leisure education 
for people with special needs is important to "develop their human capacities to an optimal degree. Through leisure experiences, individuals are enabled to live more satisfying, enjoyable and productive lives than when such opportunities are not accessible. Quality of life should be fundamental for all" (pp. 57-58). In a context for life-long learning, Spector and CohenGewerc (2001) argued that leisure is a "journey" of discovering one's uniqueness to grow and experience a meaningful and enriched life because "in leisure, one can be oneself" (p. 53).

Highlighting the developmental value of leisure, Kleiber (2001) suggested that the experience of disengagement is as important as a context for engagement (e.g., serious leisure) to facilitate optimal human development. Integrating these two opposing frameworks, Kleiber described several key functions of leisure for learning and development including: becoming capable ("the cultivation of leisure-related interests and skills," p. 6), becoming secure (mainly through relaxing leisure as a context for recovery and reflection), defining self in relation to others (leisure as an opportunity to enrich self and social identities), connecting intimacy with others (e.g., love and companionship throughout the life-span), and playing a part in something bigger than oneself (specifically through volunteerism for self-renewal). Also, Kleiber emphasized the function of creating meaning through feeling capable, becoming secure, defining oneself, connecting with others, and contributing to others or society, as pointed out above. Kleiber concluded that leisure is an important context for education and human development throughout the life course to effectively deal with developmental challenges whenever they occur, which is then critical to enhance the quality of people's lives.

\subsection{Concluding Remarks}

Recent leisure literature has emphasized the significant role of leisure in meaning-making explicitly, which has implications for promoting people's QOL. For example, Hutchinson (2004) argued that "leisure can be generative of a range of personal, familial, social, and cultural meanings," possibly facilitated by "a sense of connection, accomplishment, self/relationship/cultural affirmation, hope, control, etc." (p. 31). Caldwell (2005) identified several, intertwined aspects of leisure that can generate meanings including a context for: self-determined behaviour, competence, social relationships, selfreflection and -affirmation, identity development, and transcending negative life events. Iwasaki et al.'s (2006) qualitative, interpretive study in Winnipeg, Manitoba provided evidence that active leisure can offer an opportunity for gaining one's valued meanings such as: social, spiritual, cultural, 
altruistic, and/or empowerment, which are closely tied to the identities of people and the cultural contexts of their lives. For example, Aboriginal participants emphasized the use of culturally appropriate forms of leisure-like activities (e.g., social gatherings, Aboriginal dancing) in coping with stress (e.g., racism, health-related stress), as illustrated by one Aboriginal woman with a disability to gain social and cultural meanings - "Belonging to groups, just for get-togethers. They're all my culture, they're all Native. They share so many wonderful stories with me, and it makes me feel good and happy." Based on her own research and extensive literature review on the topic of leisure space among women (particularly, disadvantaged and marginalized groups of women world-wide), Wearing (1998) concluded that people from different cultural backgrounds can gain a diverse array of meanings from enriching leisure experiences, and leisure spaces can provide the context for personal, communal, and political growth. Likewise, Henderson and Frelke (2000) suggested that "leisure spaces can be constructed as meaningful places" particularly in a culturally safe and relevant context (p. 23).

Meaning-making through leisure can then potentially lead to the promotion of people's life quality in various cultural contexts, as evident in the review of literature in this paper. Major pathways or mechanisms that can facilitate meaning-making and life-quality-enhancement highlighted in this review paper include: (a) positive emotions and wellbeing experienced from leisure, (b) positive identities and self-esteem gained from leisure, (c) social and cultural connections and a harmony developed through leisure, and (d) leisure's contribution to learning and human development across the lifespan. Also, emphasized in this paper is the role of leisure as a context for realizing and utilizing human strengths and resilience. It is important, however, to stress that in people's quest for a meaningful life, the benefits of meaning-making through leisure involve both "remedying the bad" and "enhancing the good," as shown throughout this paper. Despite these benefits, we should not ignore that leisure experiences are socially and culturally constructed and shaped by the inequalities of society (Sasidharan, 2002). Thus, the reality of power imbalance and inequalities should be acknowledged and appropriately addressed socially, culturally, and politically. Particularly, providing culturally relevant and meaningful leisure opportunities for less privileged population groups world-wide is clearly a top priority.

Although I have attempted in this paper to highlight perspectives about leisure and QOL in non-dominant cultural contexts beyond Euro-North American contexts, there is clearly imbalance with respect to our understanding about these perspectives in a global, international context. Thus, a more systematic and intensive effort is needed to uncover the realities of lives 
among non-dominant groups of people worldwide including the contribution of leisure to meaning-making and life-quality enhancement. The voices of these people around the world should be respectfully acknowledged and brought forward to facilitating empowerment and positive social change in culturally appropriate ways. As emphasized by Shin and Rutkowski (2003), "quality, like beauty, lies in the eyes of the beholder" (p. 511).

\section{ACKNOWLEDGEMENT}

An earlier version of this paper was presented at the World Leisure Consensus Symposium, World Leisure Expo 2006, Hangzhou, China.

\section{REFERENCES}

Amusa, L.O., M. Wekesa, T.L. Adolph, B. Kalui, E. Busang and K. Thaga: 2001, 'Providing leisure and recreation needs for a developing economy: The case of Botswana', in F.H. Fu and H. Ruskin (eds.), Physical Fitness and Activity in the Context of Leisure Education, Dr. Stephen Hui Research Centre for Physical Education and Wellness, Hong Kong Baptist University, Hong Kong, China, pp. 269-291.

Atkinson, J. and C. Ober: 1995, 'We Al-Li 'Fire and Water': A process of healing', in K.M. Hazlehurst (ed.), Popular Justice and Community Regeneration: Pathways to Indigenous Reforms, Praeger, Westport, HCT, pp. 201-218.

Baker, D.A. and R.J. Palmer: 2006, 'Examining the effects of perceptions of community and recreation participation on quality of life', Social Indicators Research 75, pp. 395-418.

Balsam, K.F., B. Huang, K.C. Fieland, J.M. Simoni and K.L. Walters: 2004, 'Culture, trauma, and wellness: A comparison of heterosexual and lesbian, gay, bisexual, and two-spirit Native Americans', Cultural Diversity and Ethnic Minority Psychology 10(3), pp. 287-301.

Baumeister, R.F.: 1991, Meanings of Life (Guilford, New York).

Baumeister, R.F. and K.D. Vohs: 2002, 'The pursuit of meaningfulness', in C.R. Snyder and S.J. Lopez (eds.), Handbook of Positive Psychology, Oxford University Press, London, pp. 608-618.

Bishop, M.: 2005, 'Quality of life and psychosocial adaptation to chronic illness and disability: Preliminary analysis of a conceptual and theoretical synthesis', Rehabilitation Counseling Bulletin 48, pp. 219-232.

Bowleg, L., J. Huang, K. Brooks, A. Black and G. Burkholder: 2003, 'Triple jeopardy and beyond: Multiple minority stress and resilience among Black lesbians', Journal of Lesbian Studies 7(4), pp. 87-108.

Bramante, A.C.: 2004, 'Fostering human resources in the leisure field: 'Serious leisure' and the potential role of volunteers: A proposal for developing countries', in R.A. Stebbins and M. Graham (eds.), Volunteering as Leisure/Leisure as Volunteering, CABI Publishing, Cambridge, MA, pp. 225-240.

Bramston, P., G. Pretty and H. Chipuer: 2002, 'Unravelling subjective quality of life: An investigation of individual and community determinants', Social Indicators Research 59, pp. 261-274.

Cabeza, M.C.: 2000, Ocio Humanista [Humanistic Leisure] (Universidad de Deusto, Bilbao, Spain). 
Caldwell, L.L.: 2005, 'Leisure and health: Why is leisure therapeutic?', British Journal of Guidance and Counselling 33(1), pp. 7-26.

Canales, M.K.: 2004, 'Taking care of self: Health care decision making of American Indian women', Health Care for Women International 25, pp. 411-435.

Chin, J.L.: 1993, 'Toward a psychology of difference: Psychotherapy for a culturally diverse population', in J.L. Chin, V. CancelaDe La and Y.M. Jenkins (eds.), Diversity in Psychotherapy: The Politics of Race, Ethnicity, and Gender, Praeger, Westport, CT, pp. 69-91.

Cummins, B.: 1998, QOL Definitions and Terminology (International Society for Quality-of-Life Studies, Blackburg, VA).

Csikszentmihalyi, M.: (1990). Flow: The Psychology of Optimal Experience (Harper Perennial, New York).

Damodaran, A., A. Malathi, N. Patil, N. Suryavansihi and S. Marathe: 2002, 'Therapeutic potential of yoga practices in modifying cardiovascular risk profile in middle aged men and women', Journal of Association Physicians India 50, pp. 633-640.

Davis, C.G., S. Nolen-Hoeksema and J. Larson: 1998, 'Making sense of loss and benefiting from the experience: Two construals of meaning', Journal of Personality and Social Psychology 75 , pp. 561-574.

Diener, E. and E.M. Suh (eds.): 2000, Culture and Subjective Well-being (Well-being and Quality of Life) (MIT Press, Cambridge, MA).

Folkman, S. and J.T. Moskowitz: 2000, 'Positive affect and the other side of coping', American Psychologist 55(6), pp. 647-654.

Fox, K.M., S. Ryan, J. Dyck, B. Chivers, L. Chuchmach and S. Quesnel: 1998, 'Cultural perspectives, resilient Aboriginal communities, and recreation', Journal of Applied Recreation Research 23, pp. 147-191.

Frankl, V.: 1985, Man's Search for Meaning (Washington Square Press, New York).

Frederickson, B.L.: 2002, 'Positive emotions', in C.R. Snyder and S.J. Lopez (eds.), Handbook of Positive Psychology, Oxford University Press, London, pp. 120-134.

Garrett, M.T. and J.E. Myers: 1996, 'The rule of opposites: A paradigm for counseling Native Americans', Journal of Multicultural Counseling and Development 24, pp. 89-104.

Gong, B.: 1998, Chinese Leisure (Shanghai Antique Press, Shanghai).

Gordon, M.: 1964, Assimilation in American Life: The Role of Race, Religion, and National Origin (Oxford University Press, New York).

Gotay, C.C.: 2004, 'Quality of life in culturally diverse cancer patients', in R.J. Moore and D. Spiegel (eds.), Cancer, Culture and Communication, Kluwer Academic/ Plenum Publishers, New York, pp. 55-75.

Graziano, K.J.: 2004, 'Oppression and resiliency in a post-apartheid South Africa: Unheard voices of Black gay men and lesbians', Cultural Diversity and Ethnic Minority Psychology 10(3), pp. 302-316.

Harada, M.: 2004, 'Japan', in G. Cushman, A.J. Veal and J. Zuzanek (eds.), Free Time and Leisure Participation: International Perspectives, CABI Publishing, Cambridge, MA, pp. 153-162.

Henderson, K.A. and C.E. Frelke: 2000, 'Space as a vital dimension of leisure: The creation of place', World Leisure Journal 42(3), pp. 18-24.

Hewitt, J.P.: 2002, 'The social construction of self-esteem', in C.R. Snyder and S.J. Lopez (eds.), Handbook of Positive Psychology, Oxford University Press, London, pp. 135-147.

Hutchinson, S.L.: 2004, 'Negative life events and the creation of meaning in leisure', in F.H. Fu, D. Markus and T.K. Tong (eds.), Negative Events in the Life cycle: Leisure and Recreation as a Counteraction, Dr. Stephen Hui Research Centre for Physical Education and Wellness, Hong Kong Baptist University, Hong Kong, China, pp. 22-33.

Iwasaki, Y., J. Bartlett and J. O'Neil: 2004, 'An examination of stress among Aboriginal women and men with diabetes in Manitoba, Canada', Ethnicity and Health 9(2), pp. 189-213. 
Iwasaki, Y., J. Bartlett and J. O'Neil: 2005, 'Coping with stress among Aboriginal women and men with diabetes in Winnipeg, Manitoba', Social Science and Medicine 60(5), pp. 977-988.

Iwasaki, Y., K. MacKay, J. Mactavish, J. Ristock and J. Bartlett: 2006, 'Voices from the margins: Stress, active living, and leisure as a contributor to coping with stress', Leisure Sciences 28, pp. 163-180.

Jennings, R.: 2001, 'Life of leisure: Things move pretty slowly in Chengdu, and generations of locals wouldn't have it any other way', Far Eastern Economic Review 164(37), pp. 76.

Juniu, S. and K.A. Henderson: 2001, 'Problems in researching leisure and women: Global considerations', World Leisure Journal 43(4), pp. 3-10.

Kanahele, G.S.: 1982, Hawaiian Renaissance (Project WAIAHA, Honolulu, HI).

Kao, S., K.L. Lai, H.C. Lin, H.S. Lee and H.C. Wen: 2005, 'WHOQOL-BREF as predictors of mortality: A two-year follow-up study at veteran homes', Quality of Life Research 14, pp. 1443-1454.

Karlis, G.: 2004, Leisure and Recreation in Canadian Society: An Introduction (Thompson Educational Publishing, Toronto, Ontario).

Keltner, D. and G.A. Bonanno: 1997, 'A study of laughter and dissociation: Distinct correlates of laughter and smiling during bereavement', Journal of Personality and Social Psychology 73, pp. 687-702.

Kitaoka, S.K.: 2005, 'Multicultural counseling competencies: Lessons from assessment', Journal of Multicultural Counseling and Development 33(1), pp. 37-47.

Kleiber, D.A.: 2001, 'Developmental intervention and leisure education: A life span perspective', World Leisure Journal 43(1), pp. 4-10.

Kloeze, J.W.: 2001, 'Integration through leisure? Leisure time activities and the integration of Turkish families in Arnhem and Enschede in the Netherlands', World Leisure Journal 43(1), pp. 52-61.

Kousha, M. and N. Mohseni: 1997, 'Predictors of life satisfaction among urban Iranian women: An exploratory analysis', Social Indicators Research 40(3), pp. 329-357.

Kovac, D.: 2004, 'Quality of life: A megaconcept of coming époque', Psychology Science 46(supplement 1), pp. 167-186.

Kumar, S.: 2004, 'Perspectives on well-being in the Indian tradition', Journal of Indian Psychology 22(2), pp. 63-72.

Leung, K.K., E.C. Wu, B.H. Lue and L.Y. Tang: 2004, 'The use of focus groups in evaluating quality of life components among elderly Chinese people', Quality of Life Research 13, pp. 179-190.

Lloyd, K. and C. Auld: 2002, 'The role of leisure in determining quality of life: Issues of content and measurement', Social Indicators Research 57, pp. 43-71.

Lloyd, K. and D.E. Little: 2005, “Quality of life, Aren’t we always searching for that?”: How women can achieve enhanced quality of life through participation in outdoor adventure recreation?', Leisure/Loisir: Journal of the Canadian Association for Leisure Studies 29(2), pp. $147-180$.

Lopez, S.J., E.C. Prosser, L.M. Edwards, J.L. Magyar-Moe, J.E. Neufeld and H.N. Rasmussen: 2002, 'Putting positive psychology in a multicultural context', in C.R. Snyder and S.J. Lopez (eds.), Handbook of Positive Psychology, Oxford University Press, London, pp. 700-714.

Marafa, L.M. and F. Yung: 2004, 'Changes in participation in leisure and outdoor recreation activities among Hong Kong people during the SARS outbreak', World Leisure Journal 46(2), pp. 38-47.

Martin, W.H. and S. Mason: 2003, 'Leisure in three Middle Eastern countries', World Leisure Journal 45(1), pp. 37-46. 
McAvoy, L., D. McDonald and M. Carlson: 2003, 'American Indian/First Nation place attachment to park lands: The case of the Nuu-chah-nulth of British Columbia', Journal of Park and Recreation Administration 21(2), pp. 84-104.

McDonald, D. and L. McAvoy: 1997, 'Native Americans and leisure: State of the research and future directions', Journal of Leisure Research 29(2), pp. 145-166.

Mantero, J.C.: 2000, 'Leisure and tourism', in E. Garcia and F. Lobo (eds.), Leisure in a Globalised Society, Servićo Social Do Comércio, Sāo Paulo, Brazil.

Michalos, A.C.: 2003, Essays on the Quality of Life 19 (Kluwer Academic Publishers, Boston, MA).

Michalos, A.C.: 2005, 'Arts and the quality of life: An exploratory study', Social Indicators Research 71, pp. 11-59.

Michalos, A.C. and B.D. Zumbo: 2003, 'Leisure activities, health and the quality of life', in A.C. Michalos (ed.), Essays on the Quality of Life, 19, Kluwer Academic Publishers, Boston, MA, pp. 217-238.

Moore, R. and N. Cosco: 2000, 'Rich lives in poor neighbourhoods: Women's role in building inclusive communities', in E. Garcia and F. Lobo (eds.), Leisure in a Globalised Society, Servićo Social Do Comércio, Sāo Paulo, Brazil.

Nagla, M.: 2005, 'Leisure, food, and health: Practices and attitudes of rural and urban people in India', World Leisure Journal 47(1), pp. 24-31.

Ng, T.P., L.C.C. Lim, A. Jin and N. Shinfuku: 2005, 'Ethnic differences in quality of life in adolescents among Chinese, Malay and Indians in Singapore', Quality of Life Research: An International Journal of Quality of Life Aspects of Treatment, Care and Rehabilitation. 14(7), pp. 1755-1768.

Nosek M.A., R.B. Hughes, C.A. Howland, M.E. Young, P.D. Mullen and M.L. Shelton: 2004, 'The Meaning of Health for Women with Physical Disabilities: A qualitative analysis', Family and Community Health 27 , pp. 6-21.

O'Neil, J.D.: 1986, 'The politics of health in the fourth world: A northern Canadian example', Human Organization 45, pp. 119-128.

Patterson, I.: 2001, 'Serious leisure as a positive contribution to social inclusion for people with intellectual disabilities', World Leisure Journal 43(3), pp. 16-24.

Porter, J.R. and R.E. Washington: 1993, 'Minority identity and self-esteem', Annual Review of Sociology 19, pp. 139-161.

Prime Minister's Office: 1983, The Public Census on Lifestyle (Government Printing Office, Tokyo).

Ravenscroft, N., A. Church and P. Gilchrist: 2005, 'The ontology of exclusion: A European perspective on leisure constraints research', in E.L. Jackson (ed.), Constraints to Leisure, Venture Publishing, Inc, State College, PA, pp. 321-335.

Ren, X.S., B. Amick, L. Zhou and B. Gandek: 1998, 'Transition and psychometric evaluation of a Chinese version of the SF-36 Health Survey in the United States', Journal of Clinical Epidemiology 51, pp. 1129-1138.

Ritsner, M., R. Kurs, A. Gibel, Y. Ratner and J. Endicott: 2005, 'Validity of an abbreviated Quality of Life Enjoyment and Satisfaction Questionnaire (Q-LES-Q-18) for schizophrenia, schizoaffective, and mood disorders patients', Quality of Life Research 14, pp. 1693-1703.

Rock, M.: 2003, 'Sweet blood and social suffering: Rethinking cause-effect relationships in diabetes, distress, and duress', Medical Anthropology 22, pp. 131-174.

Rolnik, R.: 2000, 'Leisure and quality of urban life', in E. Garcia and F. Lobo (eds.), Leisure in a Globalised Society, Servićo Social Do Comércio, Sāo Paulo, Brazil.

Rondon, M.B.: 2003, 'From Marianism to terrorism: The many faces of violence against women in Latin America', Archives of Women's Mental Health 6, pp. 157-163.

Ryff, C.D. and B. Singer: 2000, 'Interpersonal flourishing: A positive health agenda for the new millennium', Personality and Social Psychology Review 4, pp. 30-44. 
Ryff, C.D. and B. Singer: 2003, 'Ironies of health condition: Well-being and health on the way to mortality', in L.G. Aspinwall and U.M. Staudinger (eds.), A Psychology of Human Strengths: Fundamental Questions and Future Directions for a Positive Psychology, American Psychological Association, Washington, DC, pp. 271-288.

Salzman, M.B. and M.J. Halloran: 2004, 'Cultural trauma and recovery: Cultural meaning, selfesteem, and the reconstruction of the cultural anxiety buffer', in J. Greenberg, S.L. Koole and T. Pyszczynski (eds.), Handbook of Experimental Existential Psychology, The Guilford Press, New York, pp. 231-246.

Samdahl, D. and N. Jekubovich: 1997, 'A critique of leisure constraints: Comparative analyses and understandings', Journal of Leisure Research 29, pp. 430-452.

Sandlund, E.S. and T. Norlander: 2000, 'The effects of Tai Chi Chuan relaxation and exercise on stress responses and well-being: An overview of research', International Journal of Stress Management 7, pp. 139-149.

Sasidharan, V.: 2002, 'Special issue introduction: Understanding recreation and the environment within the context of culture', Leisure Sciences 24, pp. 1-12.

Schaller, K.J.: 1996, 'Tai Chi Chih-an exercise option for older adults', Journal of Gerontological Nursing 22, pp. 12-17.

Schalock, R.L., I. Brown, R. Brown, R. Cummins, D. Felce, L. Matikka, K. Keith and T. Parmenter: 2002, 'Conceptualization, measurement, and application of quality of life for persons with intellectual disabilities: Report of an international panel of experts', Mental Retardation 40, pp. 457-470.

Shalhoub-Kevorkian, N.: 2003, 'Liberating voices: The political implications of Palestinian mothers narrating their loss', Women's Studies International Forum 26(5), pp. 391-407.

Sharma, V.: 2002, 'Leisure of the aged and social development: An Indian model', World Leisure Journal 44(3), pp. 16-23.

Shaw, S. and G. Karlis: 2002, 'Sister-city partnerships and cultural recreation: The case of Scarborough, Canada and Sagamihara, Japan', World Leisure Journal 44(4), pp. 44-50.

Sheykhi, M.T.: 2004, 'Globalizing influences on leisure: A perspective from Iran', World Leisure Journal 46(4), pp. 59-67.

Shin, D.C. and C.P. Rutkowski: 2003, 'Subjective quality of Korean life in 1981 and 2001', Social Indicators Research 62, pp. 509-534.

Shoarinezhad, A.A.: 1994, Growth Psychology of the Adults (Payam-e-Azadi Publishers, Tehran, Iran).

Silverstein, M. and M.G. Parker: 2002, 'Leisure activities and quality of life among the oldest old in Sweden', Research on Aging 24, pp. 528-547.

Sivan, A., R. Robertson and S. Walker: 2004, 'Hong Kong', in G. Cushman, A.J. Veal and J. Zuzanek (eds.), Free Time and Leisure Participation: International Perspectives, CABI Publishing, Cambridge, MA, pp. 127-140.

Spector, C. and E. Cohen-Gewerc: 2001, 'From education to initiation: Leisure as a second chance', World Leisure Journal 43(3), pp. 48-53.

Stathi, A. and A. Avgerinos: 2001, 'Bathing in the healing waters: A case-study of the development of thermal spas in Greece', World Leisure Journal 43(1), pp. 41-51.

Stebbins, R.A. and M. Graham (eds.): 2004, Volunteering as Leisure/Leisure as Volunteering (CABI Publishing, Cambridge, MA).

Suh, E.M. and S. Oishi: 2004, 'Culture and subjective well-being: Introduction to the special issue', Journal of Happiness Studies 5, pp. 219-222.

Sukenik, S., D. Flusser and M. Abu-Shakra: 1999, 'The role of spa therapy in various rheumatic diseases', Rheumatic Disease Clinics of North America 25, pp. 883-900.

Tao, G., F. Chen, X. Liu, et al.: 1998, 'Analysis of related factors to life satisfaction of 1380 old people in Beijing', Chinese Mental Health Journal 12, pp. 338-340. 
The Group, WHOQOL: 1998, 'The World Health Organization quality of life assessment (WHOQOL): Development and general psychometric properties', Social Science and Medicine 46(12), pp. 1569-1585.

Thompson, S.J. and S.M. Gifford: 2000, 'Trying to keep a balance: The meaning of health and diabetes in an urban Aboriginal community', Social Science and Medicine 51, pp. 1457-1472.

Tsey, K. and A. Every: 2000, Evaluation of an Aboriginal Empowerment Program (Australia Government Publishing Service, Canberra).

Tugade, M.M. and B.L. Frederickson: 2004, 'Resilient individuals use positive emotions to bounce back from negative emotional experiences', Journal of Personality and Social Psychology 86, pp. 320-333.

Veenhoven, R.: 2000, 'The four qualities of life: Ordering concepts and measures of the good life', Journal of Happiness Studies 1, pp. 1-39.

Wang, J. and L.A. Stringer: 2000, 'The impact of Taoism on Chinese leisure', World Leisure Journal 42(3), pp. 33-41.

Wang, N.: 2005, 'From leisure as ideology to leisure as industry: Changing leisure policies in China', World Leisure Journal 47(1), pp. 5-11.

Wearing, B.: 1998, Leisure and Feminist Theory (Sage Publications, London, England).

Wendel-Vos, G.C.W., A.J. Schuit, M.A.R. Tijhuis and D. Kromhout: 2004, 'Leisure time physical activity and health-related quality of life: Cross-sectional and longitudinal associations', Quality of Life Research 13, pp. 667-677.

Werthein, J.: 2000, 'A new ethic for unemployment and free time', in E. Garcia and F. Lobo (eds.), Leisure in a Globalised Society, Servićo Social Do Comércio, Sāo Paulo, Brazil.

Wolf, S.L., C. Coolger and T. Xu: 1997, 'Exploring the basis for Tai Chi Chuan as a therapeutic exercise approach', Archives of Physical Medicine 78, pp. 886-892.

World Health Organization: 1997, WHOQOL: Measuring Quality of Life (Author, Geneva, Switzerland).

World Leisure Board: 2000a, 'World Leisure international position statement on leisure education and community development', World Leisure Journal 42(3), pp. 54-56.

World Leisure Board: 2000b, 'World Leisure international position statement on leisure education and populations of special needs', World Leisure Journal 42(3), pp. 57-59.

Yang, W.Y.: 1998, Chinese Jingjie (Shanghai Antique Press, Shanghai).

Yau, M.K.-S. and T.L. Packer: 2002, 'Health and well-being through T'ai Chi: Perceptions of older adults in Hong Kong', Leisure Studies 21, pp. 163-178.

Yu, P. and D.L. Berryman: 1996, 'The relationship among self-esteem, acculturation, and recreation participation of recently arrived Chinese immigrant adolescents', Journal of Leisure Research 28, pp. 251-273.

Yuen, B.: 1996, 'Use and experience of neighbourhood parks in Singapore', Journal of Leisure Research 28, pp. 293-311.

Department of Therapeutic Recreation

College of Health Professions

Temple University

Suite 313, 1700 North Broad Street

PA 19122, Philadelphia

E-mail:yiwasaki@temple.edu 